\title{
Perancangan Ulang Kursi Roda Manual Menggunakan Kriteria Standar ISO 7176-5
}

\author{
Ayu Anggit Pradita*), Ilham Priadythama, dan Susy Susmartini \\ Program Studi Teknik Industri, Fakultas Teknik, Universitas Sebelas Maret, Jl. Ir. Sutami 36 A Kentingan, Surakarta, \\ 57126, Indonesia
}

DOI: 10.20961/performa.17.1.19068

\begin{abstract}
Abstrak
Di Indonesia, Kementerian Kesehatan Republik Indonesia (2014) menyatakan bahwa persentase penyandang cacat yang memiliki keterbatasan dalam berjalan dan menaiki tangga adalah 10,26\% dari total orang yang lumpuh. Saat ini, peralatan yang sering digunakan adalah kursi roda, namun ketersediaan kursi roda yang memenuhi standar ISO 7176-5 masih sangat terbatas karena mahal dan harus diimpor. Di Indonesia, kursi roda didistribusikan yang bersaing di pasar komersial didominasi oleh produk Cina dan beberapa pembuat lokal. Tujuan dari penelitian ini adalah untuk mendesain kembali kursi roda manual yang memenuhi kriteria ISO 7176-5. Penelitian ini menggunakan ISO 7176-5 sebagai desain referensi untuk mendesain ulang rangka utama kursi roda awal. Penelitian dimulai dengan membandingkan dan mengamati 2 jenis kursi roda $A$ dan B di pasar komersial. 2 kursi roda $(A$ dan B) diukur dan dibandingkan berdasarkan dimensi ISO 7176-5 yang terdiri dari 27 item. Dari pengukuran dan perbandingan, kursi roda A dipilih sebagai desain yang direferensikan karena mereka memiliki jumlah penyesuaian lebih banyak. Setelah itu, dimensi kursi roda A akan disesuaikan dengan ISO 7176-5 dan akan diuji dengan perangkat lunak Autodesk Inventor untuk menentukan kekuatan dari frame utama. Kesimpulan dari penelitian ini adalah bahwa hasil dari kerangka yang disarankan terdiri dari perpindahan, von misses stress dan faktor keamanan yang dinyatakan aman. Selain itu, dimensi kursi roda yang disarankan memenuhi ISO 7176-5 yang menjamin keamanan dan kenyamanan bagi pengguna.
\end{abstract}

Kata kunci: Kursi Roda, ISO, Displacement, Von Misses Stress, Safety Factor.

Abstract
In Indonesia, the Ministry of Health of the Republic of Indonesia (2014) states that the percentage of persons with disabilities who have limitation in walking and climbing up the stairs are $10.26 \%$ from the total of disable people. Currently, the equipment which is used frequently is wheelchair, nevertheless, the availability of the wheelchair that fulfill the standard of ISO 7176-5 still deeply limited because it's pricey and should be imported. In Indonesia, the distributed wheelchair which competes in the commercial market is dominated by Chinese product and some local makers. The purpose of the research is to redesign manual wheelchairs which fulfill the criteria ISO 7176-5. The research is using ISO 7176-5 as a reference design to redesign the main frames of initial wheelchair. The research is begun by comparing and observing 2 types of wheelchairs A and B in commercial market. The 2 wheelchairs (A and B) are measured and compared based on the ISO 7176-5 dimension which consists of 27 items. From the measurement and comparison, the wheelchair A is chosen as referenced design because they have more adjustment amount. After that, the dimensions of wheelchair A will be adjusted to ISO 7176-5 and will be tested with Autodesk Inventor software to determine the strength of the main frames. The conclusion of the research is that the result of the suggested frame consist of displacement, von misses stress and safety factor which is revealed as safe. In addition, the dimension of the suggested wheelchair fulfill ISO 7176-5 which guarantees safety and comfort for the users.

Keyword : Wheelchair, ISO, Displacement, Von Misses Stress, Safety Factor.

\section{Pendahuluan}

Kursi roda (wheelchair) adalah alat yang digunakan untuk meningkatkan kemampuan mobilitas bagi orang yang memiliki kekurangan, seperti orang yang cacat fisik (khususnya penyandang cacat kaki), pasien rumah sakit yang tidak diperbolehkan untuk melakukan banyak aktivitas fisik, orang tua, lanjut usia, dan orang-orang yang memiliki resiko tinggi untuk terluka bila berjalan sendiri (Wakhid, 2011). Sekitar 10\% dari populasi global yaitu sekitar 65 juta orang memerlukan kursi roda. Di Indonesia, Kementrian Kesehatan RI (2014) menyatakan bahwa presentase penyandang disabilitas yang mengalami keterbatasan berjalan atau naik tangga adalah $10,26 \%$ dari total seluruh penyandang disabilitas di Indonesia. Menurut English Wheelchair Guidelines, kursi roda adalah salah satu alat bantu yang paling umum digunakan untuk meningkatkan mobilitas pribadi.

${ }^{*}$ Korespondensi : ayuape@gmail.com 
Saat ini, ketersediaan kursi roda yang memenuhi standar ISO dikuasai oleh pasar Eropa dan Amerika dan masih sangat terbatas dikarenakan harga jual yang cukup mahal sehingga tidak dapat bersaing di pasar komersial. Di Indonesia, kursi roda yang beredar di pasar komersial didominasi oleh produk import dari China dan beberapa produsen dalam negeri. Baik kursi roda import dari China maupun produksi dalam negeri dipatok dengan harga yang cukup terjangkau. Namun, kedua kursi roda yang diproduksi China dan dalam negeri ini belum memenuhi ISO 7176-5 : Determination of dimensions, mass and manoeuvring space. ISO 7176-5 berisi prosedur untuk mengukur dimensi dan massa dari kursi roda manual dan kursi roda bertenaga listrik (termasuk skuter). Jenis kursi roda yang diteliti pada penelitian ini adalah kursi roda manual. Kedua kursi roda, baik dari China maupun produksi dalam negeri didominasi oleh masing-masing satu merk (merk $A$ untuk produksi China, merk B untuk produksi dalam negeri). Kursi roda merk A yang diobservasi berjumlah 5 buah dan kursi roda merk B berjumlah 3 buah. Namun, karena jenis dan merk sama, maka hasil observasi untuk masing-masing merk juga sama. Oleh karena itu, hanya salah satu dari masing-masing merk yang ditampilkan pada penelitian ini. dari hasil observasi. Dari kursi roda yang diobservasi, beberapa bagian belum memenuhi spesifikasi ISO 7176-5, antara lain seat plane angle; effective seat depth; seat surface height at front edge dan back support angle

Menyinggung perihal standar, Pemerintah Indonesia mendukung adanya standardisasi produk dengan mengeluarkan Undang-undang no. 20 tahun 2004 Pasal 3 tentang Standardisasi dan Peniliaian Kesesuaian. Suatu standar mempunyai tiga tujuan utama. Pertama, untuk meningkatkan jaminan mutu porduk, efisiensi produksi, daya saing nasional, persaingan usaha yang sehat dan transparan dalam perdagangan, kepastian usaha dan kemampuan pelaku usaha. Kedua, meningkatkan perlindungan kepada konsumen, pelaku usaha, tenaga kerja, dan masyarakat lainnya, serta negara, baik dari aspek keselamatan, keamanan, kesehatan, maupun pelestarian fungsi lingkungan hidup. Ketiga, meningkatkan kepastian, kelancaran, dan efisiensi transaksi perdagangan barang dan/atau jasa di dalam negeri dan luar negeri.

Selama ini telah banyak dilakukan penelitian untuk mengatasi kekurangan-kekurangan pada kursi roda manual. Penelitian Hartridge, dkk (1990) membahas tentang perbandingan biaya keandalan dan biaya perbaikan untuk kursi roda standar dan tidak berstandar. Standar kursi roda dapat digunakan untuk meningkatkan kualitas kursi roda dengan biaya efektif. Dari penelitian Hartridge, dkk (1990) menyimpulkan bahwa biaya perbaikan kursi roda berstandar adalah 3,5\% dari harga pembelian awal.

Dari pengamatan awal tentang kursi roda yang telah dilakukan, terlihat bahwa masih terdapat kekurangan pada kursi roda manual yaitu belum sesuai dengan spesifikasi ISO 7176-5. Untuk memenuhi standar tersebut, kursi roda manual perlu dirancang ulang. Perancangan ulang ini bertujuan untuk meningkatkan kualitas kursi roda melalui penyesuaian rancangan dengan standar ISO 7176-5. Sedangkan batasan masalah untuk penelitian ini adalah jenis kursi roda yang diteliti adalah kursi roda manual yang paling banyak di temuin di pasaran serta acuan rancang ulang kursi roda hanya berdasarkan standar internasional yang telah ditetapkan yaitu ISO 7176-5.

\section{Metode Penelitian}

Penelitian ini diawali dengan studi pendahuluan yang meliputi studi literatur dan lapangan untuk mengidentifikasi permasalahan yang terjadi pada rancangan awal kursi roda manual. Berdasarkan identifikasi masalah yang telah dilakukan tersebut kemudian digunakan untuk menyusun rumusan masalah dan tujuan masalah. Tahap selanjutnya yaitu tahap pengumpulan dan pengolahan data.

\subsection{Pengukuran Dimensi Kursi Roda}

Pengumpulan data di awali dengan pengukuran dimensi kursi roda. Stándar yang digunakan sebagai acuan pengukuran adalah ISO 7176-5 yang terdiri dari 29 item dengan 3 kelompok massa pengguna. ISO 7176-5 ini secara spesifik memuat tentang massa pengguna kursi roda, panduan pengukuran dimensi kursi roda dan jarak manuver kursi roda yang telah ditetapkan. Pada penelitian ini, item pada ISO 7176-5 yang digunakan sebagai acuan adalah kelompok pengguna dengan massa $50-125 \mathrm{~kg}$ dan hanya 27 dari 29 item. Dua item yaitu Footrest to leg dan Footrest to leg angle tidak disertakan karena bentuk kaki pengguna yang bervariasi. Terdapat 2 merk kursi roda manual yang diukur yaitu A dan B. Pengukuran dimensi bertujuan untuk mengetahui kondisi dimensi kursi roda saat ini apakah sudah memenuhi standar yang telah ditentukan. Selanjutnya, hasil pengukuran 2 merk kursi roda tersebut akan dibandingkan dengan ISO 7176-5 dan akan dipilih kursi roda dengan tingkat kesesuaian yang paling banyak dengan ISO 7176-5. Kursi roda yang terpilih akan digunakan sebagai desain referensi. 


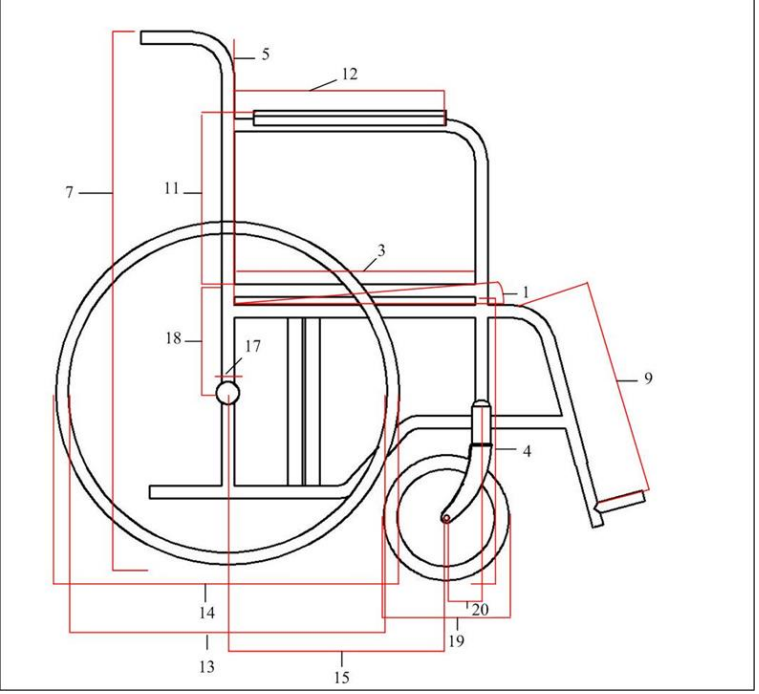

Gambar 2.1 Panduan Ukuran Kursi Roda

\subsection{Pengamatan Komponen Kursi Roda}

Pada tahap ini, dilakukan pengamatan terhadap komponen kursi roda melalui wawancara terhadap kursi roda yang terpilih. Pengamatan dilakukan pada kursi roda yang menjadi desain referensi. Tujuan dari pengamatan ini adalah mencocokkan hasil pengukuran dengan pendapat pengguna kursi roda.

\subsection{Perancangan Ulang Kursi Roda sesuai ISO 7176-5}

Kursi roda yang terpilih menjadi desain referensi akan dilakukan penyesuaian dengan ISO 7176-5. Semua dimensi yang terdapat pada kursi roda terpilih akan dirancang ulang sesuai ISO 7176-5. Tujuan dari penyesuaian ini adalah merancang kursi roda manual yang baru sesuai dengan standar yang telah ditetapkan yaitu ISO 7176-5 sehingga melalui penyesuaian ini, nantinya kursi roda akan lebih mempunyai nilai tambah karena sudah sesuai dengan strandar yang ditetapkan serta memenuhi aspek keamanan penggunanya. Perancangan kursi roda ini dibuat dengan software Autodesk Inventor 2015.

\subsection{Pengujian Rancangan Baru Kursi Roda}

Pada tahap ini,akan dilakukan pengujian rancangan kursi roda dengan finite elemen pada software Autodesk Inventor. Pengujian ini meliputi displacement, von misses stress dan safety factor. Tujuan dari pengujian ini adalah mengetahui kekuatan rangka kursi roda yang baru.

\section{Hasil dan Pembahasan}

Hasil yang diperoleh dari penelitian meliputi pengukuran dimensi kursi roda dan perancangan ulang kursi roda yang sesuai dengan ISO 7176-5.

\subsection{Pengukuran Dimensi Kursi Roda}

Jenis kursi roda yang diteliti adalah kursi roda manual. Kedua kursi roda ini diukur dan dibandingkan dengan 27 item ISO 7176-5. Studi lapangan untuk kursi roda A dilakukan di Balai Besar Rehabilitasi Sosial Bina Daksa (BBRSBD) Prof. Dr. Soeharso, sedangkan untuk kursi roda B di Gentan, Sukoharjo. Hasil pengukuran terhadap 2 merk kursi roda manual ini ditunjukkan pada tabel 3.1. 
Tabel 3.1 Hasil Pengukuran Kursi Roda

\begin{tabular}{|c|c|c|c|c|}
\hline \multirow{2}{*}{ No } & \multirow{2}{*}{ Item } & \multicolumn{3}{|c|}{ Kursi Roda } \\
\hline & & ISO 7176-5 & $\mathbf{A}$ & $\mathbf{B}$ \\
\hline 1 & Seat plane angle (degrees) & 4 & 10 & 0 \\
\hline 2 & Effetive seat depth (milimetres) & 450 & 400 & 400 \\
\hline 3 & Effective seat width (milimetres) & 450 & 450 & 410 \\
\hline 4 & Seat surface height at front edge (milimetres) & 520 & 470 & 500 \\
\hline 5 & Back support angle [backrest angle] (degrees) & 10 & 0 & 0 \\
\hline 6 & Back support height [backrest height] (milimetres) & 420 & 440 & 450 \\
\hline 7 & Handgrip height (milimetres) & 950 & 860 & 900 \\
\hline 8 & Back support width [backrest width] (milimetres) & 450 & 450 & 410 \\
\hline \multirow{2}{*}{9} & Footrest to seat (milimetres) & 450 & 370 & 460 \\
\hline & BUT NO LESS THAN : Footrest clearance (milimetres) & 40 & 120 & 30 \\
\hline 10 & Footrest length (milimetres) & 250 & 220 & 200 \\
\hline 11 & Armrest height (milimetres) & 200 & 240 & 290 \\
\hline 12 & Front of armrest to back support [front of armrast to backrest] (milimetres) & 320 & 370 & 400 \\
\hline 13 & Handrim diameter (milimetres) & 530 & 500 & 500 \\
\hline 14 & Manoeuvring wheel diameter [propelling wheel diameter] (milimetres) & 610 & 550 & 590 \\
\hline 15 & Wheelbase (milimetres) & 400 & 370 & 530 \\
\hline 16 & Camber (degrees) & 0 & 0 & 0 \\
\hline 17 & Horizontal location of wheel axle (milimetres) & 20 & 0 & 0 \\
\hline 18 & Vertical location of wheel axle (milimetres) & 184 & 200 & 230 \\
\hline 19 & Castor wheel diameter (milimetres) & 175 & 175 & 200 \\
\hline 20 & Castor trail (milimetres) & 50 & 65 & 40 \\
\hline 21 & Track of drive wheel or manoeuvring wheels [drive wheel track width] & Mid-position & Mid-position & Mid-position \\
\hline 22 & Track of castor wheels or pivot wheels [castor wheel track width] & Mid-position & Mid-position & Mid-position \\
\hline 23 & Movable wheel, horizontal position [castor stem housing position, horizontal] & Mid-position & Mid-position & Mid-position \\
\hline 24 & Movable wheel, vertical position [castor stem housing position, vertical & Mid-position & Mid-position & Mid-position \\
\hline 25 & Movable wheel, vertical axle position [castor wheel axle position, vertical] & Mid-position & Mid-position & Mid-position \\
\hline 26 & Castor rake [castor stem angle, fore-aft plane] (degrees) & Vertical $+1 /-0$ & 0 & 0 \\
\hline 27 & Castor cant [castor stem angle, lateral plane] (degrees) & Vertical +- 0,5 & 0 & 0 \\
\hline & $\begin{array}{l}\text { Jumlah Item yang Sesuai } \\
\end{array}$ & & 12 & 8 \\
\hline
\end{tabular}

Dari tabel 3.1, diketahui bahwa kursi roda A mempunyai 12 item yang sesuai dengan ISO 7176-5, sedangkan kursi roda B mempunyai 8 item yang sesuai dengan ISO 7176-5. Karena kursi roda A mempunyai jumlah kesesuaian yang paling banyak dan paling dekat, maka kursi roda A dijadikan sebagai desain referensi.

\subsection{Pengamatan terhadap Komponen Kursi Roda}

Komponen kursi roda yang diamati adalah rangka, armrest dan wheelbase. Ketiga komponen ini terpilih karena pada saat wawancara dengan pengguna kursi roda A, ketiga komponen ini yang paling banyak dikeluhkan. Kondisi awal pengguna dan kursi roda A ditunjukkan pada gambar 3.1. Hasil pengamatan ditunjukkan pada tabel 3.2.

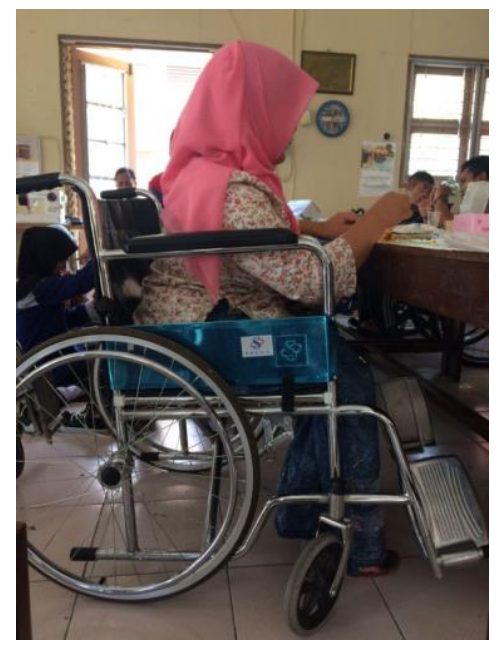

Gambar 3.1 Kursi Roda A 
Tabel 3.2 Hasil Pengukuran Kursi Roda

\begin{tabular}{|c|c|l|l|l|}
\hline No & $\begin{array}{c}\text { Komponen } \\
\text { yang } \\
\text { diamati }\end{array}$ & \multicolumn{1}{|c|}{ Hasil Pengamatan } & \multicolumn{1}{|c|}{ Penyebab } & \multicolumn{1}{c|}{ Akibat } \\
\hline 1 & Rangka & $\begin{array}{l}\text { Pengguna merasa kesulitan saat } \\
\text { mengoperasikan kursi roda }\end{array}$ & $\begin{array}{l}\text { Rangka terlalu berat dan } \\
\text { kompleks }\end{array}$ & $\begin{array}{l}\text { Memerlukan lebih banyak } \\
\text { upaya untuk menggerakan } \\
\text { kursi roda. }\end{array}$ \\
\hline 2 & Armrest & Terlalu tinggi dari tempat duduk & $\begin{array}{l}\text { Standar pabrik yang tidak } \\
\text { sesuai ISO 7176-5 }\end{array}$ & $\begin{array}{l}\text { Pengguna merasa kelelahan } \\
\text { saat mengoperasikan kursi } \\
\text { roda }\end{array}$ \\
\hline 3 & Wheelbase & $\begin{array}{l}\text { Wheelbase (jarak antara pusat } \\
\text { rear } \text { weel dan } \text { castor } \text { ) terlalu } \\
\text { dekat }\end{array}$ & $\begin{array}{l}\text { Standar pabrik yang tidak } \\
\text { sesuai ISO 7176-5 }\end{array}$ & Stabilitas berkurang \\
\hline
\end{tabular}

Dari tabel 3.2, diketahui bahwa pengguna merasa kesulitan saat mengoperasikan kursi roda A. hal itu disebabkan karena rangka terlalu berat sehingga memerlukan lebih banyak usaha dalam menggerakan kursi roda. Pada bagian armrest, kursi roda A mempunyai armrest height yang terlalu tinggi. Hal ini disebabkan oleh standar pabrik yang tidak sesuai ISO 7176-5 yang mengakibatkan pengguna merasa kelelahan saat mengoperasikan kursi roda. Pada bagian yang lain yaitu wheelbase, kursi roda A mempunyai wheelbase yang terlalu dekat.hal ini juga disebabkan oleh estándar pabrik yang tidak sesuai ISO 7176-5 yang mengakibatkan stabilitas berkurang sehingga pengguna A sering terjungkal dari kursi rodanya.

Dari hasil pengamatan yang dilakukan, terdapat kecocokkan antara 2 item yang diukur dan 2 komponen yang diamati. Armrest height kursi roda A adalah 240mm, sedangkan ISO 7176-5 menetapkan armrest height setinggi $200 \mathrm{~mm}$. Hal ini berarti, armrest height kursi roda A terlalu tinggi dari ISO 7176-5. Wheelbase pada kursi roda A yang diukur adalah 370mm, sedangkan pada ISO 7176-5, wheelbase harus berjarak $400 \mathrm{~mm}$. Karena wheelbase yang tidak sesuai ini, maka stabilitas kursi roda A berkurang sehingga menyebabkan pengguna sering terjungkal dari kursi rodanya. Hal ini sesuai dengan hasil pengamatan terhadap wheelbase kursi roda A.

\subsection{Perancangan Ulang Kursi Roda Sesuai ISO 7176-5}

Langkah selanjutnya adalah memunculkan konsep baru kursi roda dengan cara menyesuaikan semua dimensi kursi roda A dengan ISO 7176-5. Terdapat 15 item yang harus disesuaikan diantaranya seat plane angle, effective seat depth, back support angle [backrest angle], back support height [backrest height] dan handgrip height. Hasil penyesuaian kursi roda A dengan ISO 7176-5 ditunjukkan pada gambar 3.2.

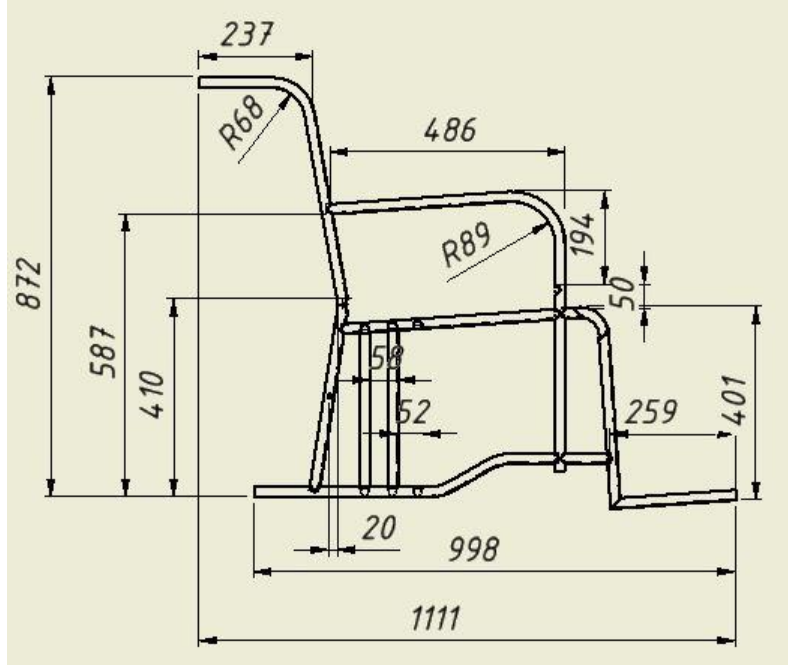

Gambar 3.2 Kursi Roda yang sudah sesuai ISO 7176-5

\subsection{Pengujian Rancangan Kursi Roda}

Rangka kursi roda yang baru akan diberikan sejumlah gaya untuk mengetahui tingkat kekuatan rancangan. Sebelum dilakukan pengujian, gaya yang mengenai rangka secara langsung dihitung terlebih dahulu. Bagian tubuh dibagi menjadi 4 menurut Chafin dan Anderson (1990) yaitu Head and Neck, Torso, Total Arm dan Total Leg. Pada penelitian ini, tubuh akan dibagi menjadi 4 yaitu bagian-bagian tubuh yang secara langsung mengenai rangka yaitu

- Bagian Atas (terdiri dari Head and Neck, Thorax, Lumbar dan Pelvis) : $\mathrm{F}_{1}$ 
- Thigh

- Lower Leg (terdiri dari Foot dan Shank)

- Arm (terdiri dari Upper Arm, Fore Arm dan Hand)

Gambar skematik rangka kursi roda yang menerima gaya ditunjukkan pada gambar 3.3
$: \mathrm{F}_{2}$

$: \mathrm{F}_{3}$

$: \mathrm{F}_{4}$

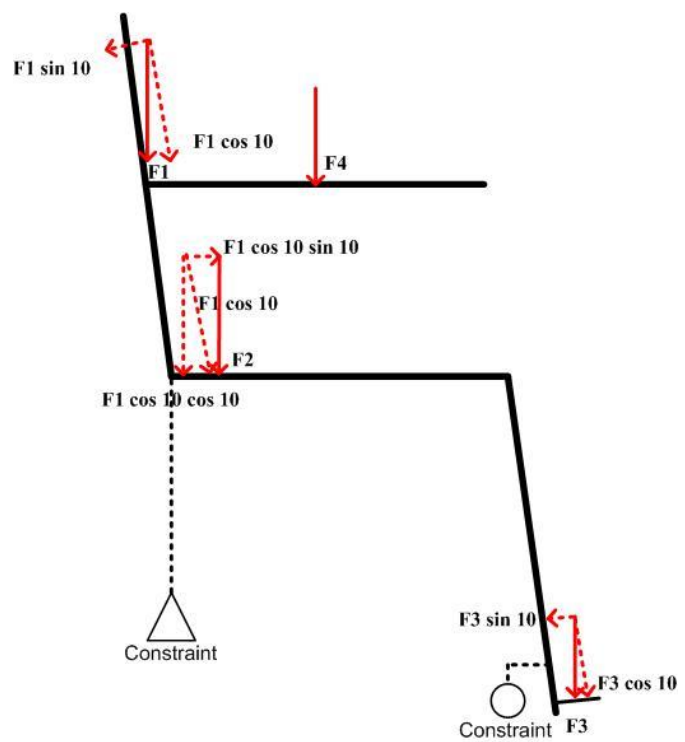

Gambar 3.3 Penjabaran Gaya yang Bekerja

Perhitungan Gaya/Force awal didasarkan pada perhitungan proporsi massa tubuh (Chafin \& Anderson, 1999) dengan massa awal $125 \mathrm{~kg}$. Selanjutnya gaya yang mengenai rangka secara langsung akan dihitung sesuai dengan besar sudut yang terdapat pada kursi roda seperti yang ditunjukkan pada gambar 3.3. Besar Gaya yang bekerja adalah sebagai berikut :

- Gaya pada Back Support Bar
Back Support Bar
$: 63,51 \mathrm{~N}$

- Gaya pada Seat Bar dan Strap
Strap
$: 70,5 \mathrm{~N}$
Seat Bar
$: 62,5 \mathrm{~N}$

- Gaya pada Footrest Frame

Footrest Frame (1) : :70,1 N

Footrest Frame (2) : : 12,4 N

- Gaya pada Arm Support Bar

Arm Support Bar

$: 63,8 \mathrm{~N}$

Setelah diketahui besar gaya yang bekerja pada masing-masing rangka, maka gaya tersebut di input pada pengujian finite elemen Autodesk Inventor 2015. Hasil pengujian meliputi displacement, von misses stress dan safety factor yang ditunjukkan pada gambar 3.4

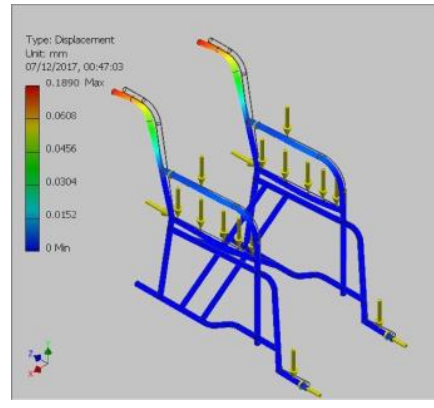

(a)

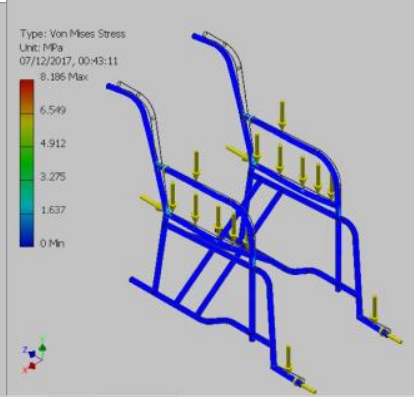

(b)

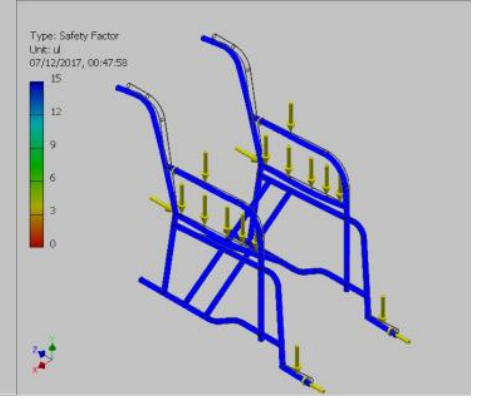

(c)

Gambar 3.10 (a) Displacement

(b) Von Misses Stress

(c) Safety Factor 
a. Displacement

Pergerakan yang terjadi akibat beban yang terdapat pada poros dengan posisi nilai terbesar berada pada tengah-tengah poros. Besar displacement maksimum pada rancangan kursi roda usulan adalah 0,189 dan 0 untuk nilai minimum

b. Von Misses Stress

Von Misses Stress digunakan untuk mengetahui tingkat keluluhan material terhadap pembebanan dari hasil pengujian. Dari gambar 12 (b) diketahui bahwa Yield Strenght untuk material High Tensile Steel sebesar 276,5 Mpa dan besar Von Misses Stress maksimum sebesar 8,186 Mpa.

c. Safety Factor

Safety factor merupakan nilai batas aman resiko kegagalan. Angka Safety factor harus melebihi angka 2. Dari gambar 12 poin c diketahui bahwa Safety factor minimum adalah sebesar 10,5 ul dan maksimum sebesar 15 ul, maka dapat dikatakan bahwa struktur tersebut aman.

\section{Simpulan}

Kursi roda awal yang dikaji belum memenuhi ISO 7176-5 yang ditetapkan. Hal ini mengakibatkan beberapa komponen yang tidak sesuai dengan ISO 7176-5 membuat pengguna menjadi tidak aman dan nyaman dalam mengoperasikan kursi roda. Kursi roda yang dilakukan rancang ulang mengalami perubahan bentuk pada rangka utama. Hasil dari rancang ulang ini adalah kursi roda usulan dapat memenuhi 22 dari 27 item ISO 7176-5. Lima ítem belum dapat dipenuhi karena rancangan belum direalisasikan atau dibuat, sehingga belum dapat dibandingkan. Kursi roda awal (A) hanya mampu memenuhi 7 dari 22 item, sedangkan kursi roda usulan mampu memenuhi 22 dari 22 item ISO 7176-5.

\section{Daftar Pustaka}

Batan, I. M. L. (2006). Pengembangan Kursi Roda Sebagai Upaya Peningkatan Ruang Gerak Penderita Cacat Kaki. Jurnal Teknik Industri vol. 8, no. 2, Desember 2006: 97-105. Diakses dari http://www.petra.ac.id/ puslit/journals/dir.php?DepartmentID=IND

Chafin, Don B., Anderson, G. I., \& Martin, B. J. (1999). Occupational Biomechanics Thrid Edition. ISBN 0471-24697-2 (cloth : alk.paper)

Guidelines on the provision of Manual Wheelchairs in less resourced settings. (2007). Diakses pada 12 Juli 2017 http://www.who.int/disabilities/publications/technology/English\%20Wheelchair\%20Guidelines\%20(E N\%20for\%20the\%20web).pdf

Hartridge, M., \& Seeger, B. S. (1990). International Wheelchair Standards: A Study of Costs and Benefits. Assistive Technologies, 2:4. doi : 10.1080/10400435.1990.10132163.

International Organization for Standardization. (2007). ISO 7176-26 : Vocabulary.

International Organization for Standardization. (2008). ISO 7176-5 : Determination of dimensions, mass and manoeuvring space.

Kementrian Kesehatan. (2014). Buletin Jendela Data dan Informasi Kesehatan Situasi Penyandang Disabilitas. Jakarta: Depkes RI.

Koontz, A. M., Brindle, E. D., Kankipati, P., Feathers, D., \& Cooper, R. A. (2010). Design Features That Affect the Maneuverability of Wheelchairs and Scooters. Arch Pyhs Med Rehabil 2010;91: 759-64.

Kusumawardani, F., Herdiman, L., \& Susmartini, S. (2016). Perancangan Ulang Kursi Roda Manual untuk Meningkatkan Mobilitas Pengguna dengan Menggunakan Metode Universal Design dan TRIZ. Joint International Conference on Electric and Chemical Engineering (ICEVT \& IMECE) 2016

Kwarciak, A. M., Cooper, R.A., Ammer, W. A., Fitzgerald, S. G., Boninger, M. L., \& Cooper, R. (2005). Fatigue Testing of Selected Suspension Manual Wheelchair Using ANSI/RESNA. Arch Pyhs Med Rehabil 2005; 86:123-9.

Undang-Undang Republik Indonesia Nomor 20 Tahun 2014 tentang Standardisasi dan Penilaian Kesesuaian.

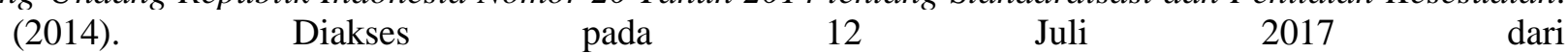
http://www.bsn.go.id/uploads/download/UU20 TAHUN 2014 TENTANG SPK1.pdf. 